Article

\title{
Dental Sealant Empowered by 1,3,5-Tri Acryloyl Hexahydro-1,3,5-Triazine and $\alpha$-Tricalcium Phosphate for Anti-Caries Application
}

\author{
Juliana Caletti Monteiro ${ }^{1}$, Michele Stürmer ${ }^{1}$, Isadora Martini Garcia ${ }^{1}$, Mary Anne Melo ${ }^{2,3}$ (D), \\ Salvatore Sauro ${ }^{4,5}\left(\mathbb{D}\right.$, Vicente Castelo Branco Leitune ${ }^{1}(\mathbb{D}$ and Fabrício Mezzomo Collares $1, *($ ) \\ 1 Dental Materials Laboratory, School of Dentistry, Federal University of Rio Grande do Sul, \\ Rua Ramiro Barcelos, 2492, Rio Branco, Porto Alegre RS 90035-003, Brazil; \\ juliana.caletti@hotmail.com (J.C.M.); mi_sturmer@hotmail.com (M.S.); isadora.garcia@ufrgs.br (I.M.G.); \\ vicente.leitune@ufrgs.br (V.C.B.L.) \\ 2 Ph.D. Program in Biomedical Sciences, University of Maryland School of Dentistry, \\ Baltimore, MD 21201, USA; MMelo@umaryland.edu \\ 3 Operative Dentistry Division, General Dentistry Department University of Maryland School of Dentistry, \\ Baltimore, MD 21201, USA \\ 4 Departamento de Odontología, Facultad de Ciencias de la Salud, Universidad CEU-Cardenal Herrera, \\ C/Del Pozo (s/n), Alfara del Patriarca, 46115 Valencia, Spain; salvatore.sauro@uchceu.es \\ 5 Department of Therapeutic Dentistry, Sechenov University of Moscow, Mozhaisky Val, 11, \\ Moscow 119435, Russia \\ * Correspondence: fabricio.collares@ufrgs.br
}

Received: 30 March 2020; Accepted: 11 April 2020; Published: 12 April 2020

\begin{abstract}
Quaternary ammonium compounds and calcium phosphates have been incorporated into dental materials to enhance their biointeractivity and preventive effects. This study aimed at evaluating the physical and chemical properties and effects against Streptococcus mutans of a dental sealant containing 1,3,5-tri acryloyl hexahydro-1,3,5-triazine (TAT) and $\alpha$-tricalcium phosphate $(\alpha$-TCP). A methacrylate-based dental sealant was initially formulated. $\alpha$-TCP and TAT (G $\alpha$-TCPTAT) were added to the experimental sealant at $2 \mathrm{wt} . \%$ each. One group was formulated without $\alpha$-TCP and TAT and used as control $\left(\mathrm{G}_{\mathrm{CTRL}}\right)$. All tested resins were analyzed for polymerization kinetics and degree of conversion (DC \%), Knoop hardness (KHN), softening in solvent $(\triangle \mathrm{KHN} \%)$, ultimate tensile strength (UTS), the contact angle with water or with $\alpha$-bromonaphthalene, surface free energy (SFE) and antibacterial activity against Streptococcus mutans in biofilm and in planktonic cells. The polymerization kinetic was different between groups, but without statistical differences in the DC $\%(p<0.05)$. KHN and $\triangle \mathrm{KHN} \%$ did not change between groups $(p>0.05)$, but $\mathrm{G}_{\alpha \text {-TCPTAT }}$ presented greater UTS compared to $\mathrm{G}_{\mathrm{CTRL}}(p<0.05)$. No differences were found for contact angle

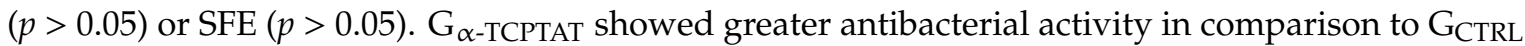
$(p<0.05)$. The formulation of dental sealants containing TAT and $\alpha$-TCP can be characterized by improved mechanical and antibacterial properties.
\end{abstract}

Keywords: dental resin; antibacterial; polymerization; remineralizing; triazines

\section{Introduction}

Dental caries is the foremost oral health problem around the world and it is one of the most common conditions affecting children [1]. Streptococcus mutans (S. mutans) presents a major role within the pathogenic biofilm that triggers dental caries. S. mutans adheres to the tooth surface and metabolizes carbohydrates, producing acids that lead to enamel demineralization for the onset of 
dental caries, as well its progression. Although dental caries is a multifactorial disease, it can be prevented and even potentially reversed during its early stages [2]. Indeed, resin sealants for pits and fissures have been used in order to reduce the incidence of new caries lesions in high-risk patients, as well as to treat non-cavitated lesions [3]. The effectiveness of sealants mainly depends on their retention and sealing; there is strong evidence that the rate of remained intact resin decreases over time [4], leading to the need for the development of novel materials with better mechanical properties. Furthermore, the current trend in material science involves the incorporation of copolymerizable antimicrobial agents and bioactive remineralizing fillers [5].

1,3,5-tri acryloyl hexahydro-1,3,5-triazine (TAT) is a quaternary ammonium compound (QAC) showing selective antibacterial properties against gram-positive pathogens [6], such as S. mutans. This compound has already been used in dental materials formulations, such as dentin bonding agents, composite resins and orthodontic adhesives [7-9]. It is a current trend to improve the therapeutics properties of dental materials by incorporating releasing or non-releasing antibacterial agents within their formulations. The disadvantage of using an antimicrobial agent that releases over time is the loss of activity [10]. Due to its tri-functional molecule - with three methacrylate groups - TAT has the ability to copolymerize with the methacrylate resin matrix and holds more extended antibacterial activity [7]. Furthermore, materials with copolymerized TAT seem to be characterized by better physical and chemical properties [9].

Furthermore, calcium phosphates have been incorporated in dental materials to induce the release of calcium and phosphates ions in order to promote mineral deposition and dental remineralization [11-13]. One of our previous studies showed that $\alpha$-tricalcium phosphate ( $\alpha$-TCP) at $2 \mathrm{wt} . \%$ in an adhesive resin was able to promote mineral deposition on dentin after selective removal of carious tissue, besides improving the bond strength and show better results among other calcium phosphates [12]. However, there is no information about the combination of TAT and $\alpha$-TCP, aiming to provide biointeractivity for dental materials. Considering that dental sealants could be improved, we decided to investigate the combined antibacterial and bioactive agents already tested by our research group for the development of a low viscosity dental resin intended for preventing the caries onset. This study aimed at evaluating the physical, chemical and antibacterial properties against Streptococcus mutans of an experimental dental sealant containing 1,3,5-tri acryloyl hexahydro-1,3,5-triazine (TAT) and $\alpha$-tricalcium phosphate $(\alpha$-TCP).

\section{Materials and Methods}

\subsection{Resin Sealants Formulation}

For resin sealants formulation, bisphenol A glycol dimethacrylate (BisGMA) at $50 \mathrm{wt} . \%$ and triethylene glycol dimethacrylate (TEGDMA) at $50 \mathrm{wt} . \%$ were used. Camphorquinone (CQ) and ethyl 4-dimethylaminobenzoate (EDAB) at $1 \mathrm{~mol} \%$, according to the monomer moles were added as a photoinitiator system. Butylated hydroxytoluene (BHT) at $0.01 \mathrm{wt} . \%$ was also used as a stabilizer. Calcium Tungstate was added as a radiopacifier agent at $30 \mathrm{wt} . \%$. Colloidal silica was added at $0.7 \mathrm{wt} . \%$ for viscosity adjustment, while $\alpha$-TCP [12] and TAT ( $\left.\mathrm{G}_{\alpha \text {-TCPTAT }}\right)$ were added to the experimental resin sealant at $2 \mathrm{wt} . \%$ each. A control resin sealant was formulated without the use of $\alpha$-TCP and TAT $\left(\mathrm{G}_{\mathrm{CTRL}}\right)$. All the chemicals listed so far were purchased from Aldrich Chemical Company, St. Louis, MI, USA. All specimens, except those for ultimate tensile strength evaluation, were prepared using a polyvinylsiloxane mold with $1 \mathrm{~mm}$ thickness and $4 \mathrm{~mm}$ diameter. Next, the resin was photoactivated for $30 \mathrm{~s}$ on each side using a light-curing unit (Radii Cal, SDI, Bayswater, Victoria, Australia) at $1200 \mathrm{~mW} / \mathrm{cm}^{2}$. The specimens for the polymerization kinetics were photoactivated for $30 \mathrm{~s}$ on the top. Figure 1 displays a schematic diagram of the experimental design and the type of assessments employed in this study. 


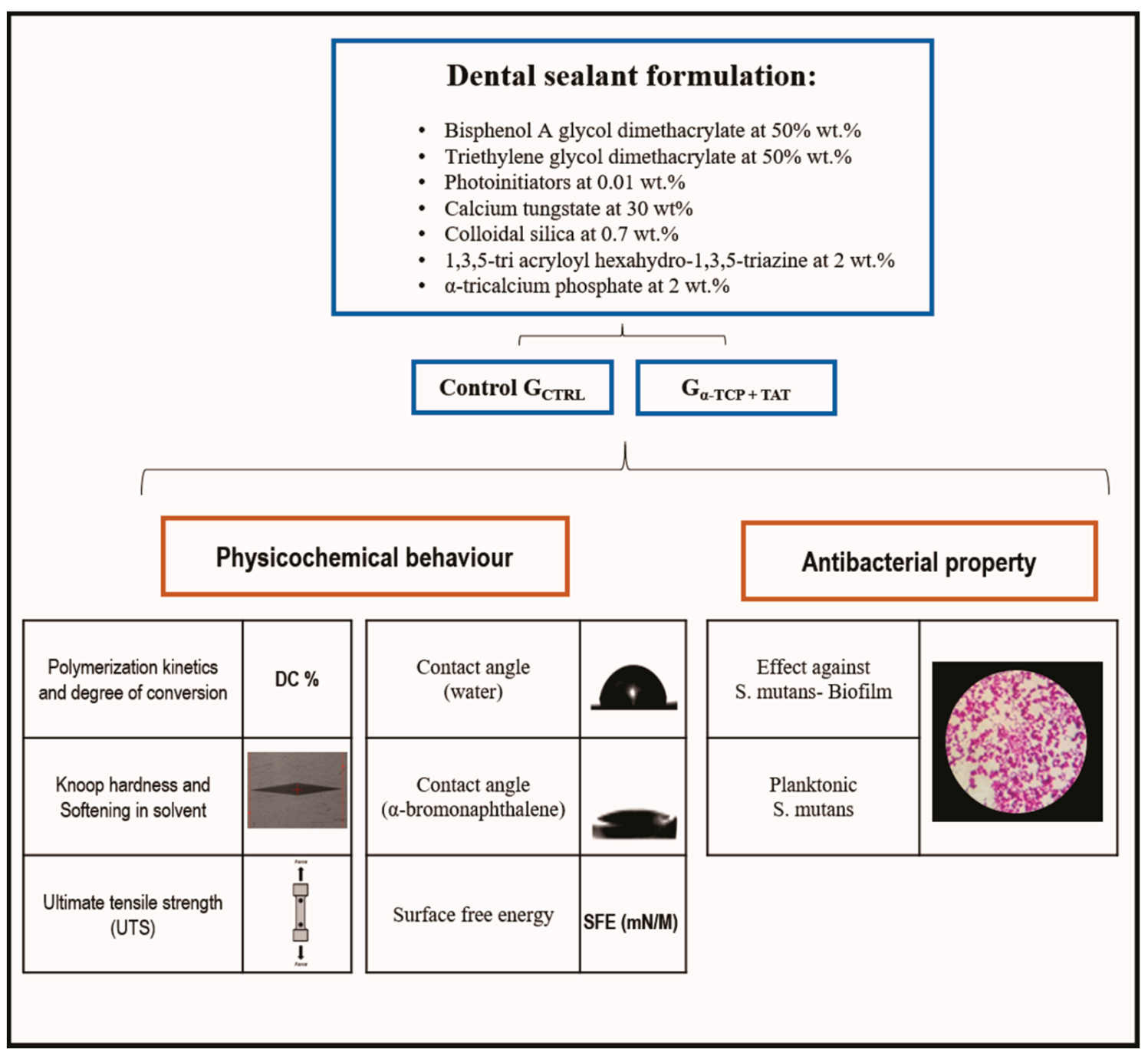

Figure 1. Schematic draw of the study design.

\subsection{Polymerization Kinetics and Degree of Conversion (DC \%)}

The polymerization kinetics and the DC \% of the experimental resin sealants were evaluated through Fourier transform infrared spectroscopy (FTIR, Bruker Optics, Ettlingen, Baden-Württemberg, Germany). Drops of the unpolymerized sealants were dispensed on the attenuated total reflectance device (ATR). Three specimens per group were photoactivated at $1 \mathrm{~mm}$ between the tip of the light-curing unit and the top of each specimen. During the photoactivation, two spectra per second were obtained in absorbance mode $\left(10 \mathrm{kHz}\right.$ velocity, $4 \mathrm{~cm}^{-1}$ resolution, Opus 6.5 software, Bruker Optics, Ettlingen, Baden-Württemberg, Germany) from 4000 to $400 \mathrm{~cm}^{-1}$. DC \% was calculated using the first spectrum of the uncured resin and the last spectrum, when the resin was totally polymerized. The DC \% was calculated using the peak at $1610 \mathrm{~cm}^{-1}$ from aromatic carbon-carbon double bond as the internal standard, along with the peak at $1640 \mathrm{~cm}^{-1}$ as an aliphatic carbon-carbon double bond [14]. The following formula was applied:

$$
\mathrm{DC} \%=100 \times\left(\frac{\text { peak height of cured aliphatic } \mathrm{C}=\mathrm{C} / \text { peak height of cured aromatic } \mathrm{C}=\mathrm{C}}{\text { peak height of uncured aliphatic } \mathrm{C}=\mathrm{C} / \text { peak height of aromatic } \mathrm{C}=\mathrm{C}}\right) \text {. }
$$

The polymerization rate (Rp) was calculated by subtracting the DC \% at a time " $\mathrm{t}$ " from the DC achieved at time " $\mathrm{t}-1$." The graphs of DC \% versus time, Rp versus time and DC \% versus Rp were plotted. 


\subsection{Knoop Hardness and Softening in Solvent}

Five specimens were prepared and embedded in self-curing acrylic resin and polished in an automatic polisher machine (Model 3v, Arotec, Cotia, São Paulo, Brazil) using silicon carbide sandpapers with decreasing grain size up to 2000 grit and under continuous irrigation using distilled water. Felt discs with alumina suspension $(0.5 \mu \mathrm{m}$, Arotec, Cotia, São Paulo, Brazil) were used for the final polishing step. After $24 \mathrm{~h}$, five indentations $(10 \mathrm{~g} / 5 \mathrm{~s})$ were performed on the top of each specimen using a digital microhardness tester (HMV 2, Shimadzu, Tokyo, Honshu, Japan) to obtain the initial Knoop hardness number (KHN1). Each group was immersed in a Becker flask with a solution of ethanol: water (70:30) for two hours and washed with distilled water for subsequent evaluation of the final Knoop hardness number (KHN2). The difference between KHN2 and KHN1 is presented as the percentual Knoop hardness reduction $(\Delta \mathrm{KHN} \%)$.

\subsection{Ultimate Tensile Strength (UTS)}

Ten specimens per group ( $8.0 \mathrm{~mm}$ long, $2.0 \mathrm{~mm}$ wide and $1.0 \mathrm{~mm}$ thickness) were prepared using a metallic matrix with a cross-sectional area of $\pm 1 \mathrm{~mm}^{2}\left( \pm 0.1 \mathrm{~mm}^{2}\right)$ and an hourglass shape. After $24 \mathrm{~h}$, the samples were glued onto metallic jigs using the cyanoacrylate resin. A micro tensile strength test was performed using a universal testing machine (EZ-SX Series, Shimadzu, Kyoto, Japan). The specimens were stressed at $1 \mathrm{~mm} / \mathrm{min}$ crosshead speed until fracture. The result in MPa was calculated by dividing the maximum force value to the fracture $(\mathrm{N})$ by the area of each sample at the constriction at the hourglass shape $\left(\mathrm{mm}^{2}\right)$.

\subsection{Contact Angle and Surface Free Energy (SFE)}

The contact angle and the surface free energy (SFE) of the experimental resin sealants were evaluated using five specimens per group. First, specimens were embedded in acrylic resin and then polished, as described in the softening in the solvent section. An optical tensiometer (Theta, Biolin Scientific, Stockholm, Stockholm, Sweden) was used with the sessile drop method with one drop of distilled water (used as a polar liquid) or $\alpha$-bromonaphthalene (used as a non-polar liquid) that was dispensed on the polymerized specimens. The drop-out size was $3.0 \mu \mathrm{L}$, the drop rate was $2.0 \mu \mathrm{L} / \mathrm{s}$, the displacement rate was $20.0 \mu \mathrm{L} / \mathrm{s}$ and the speed dispersion of water or $\alpha$-bromonaphthalene was $50 \mathrm{~mm} / \mathrm{min}$. The drop was evaluated on the polymerized specimens during $20 \mathrm{~s}$ and the mean contact angle was registered after $10 \mathrm{~s}$ after liquid contact with the surface. The SFE was obtained with the Owens-Wendt-Rabel-Kaelble (OWRK) method [15] in the OneAttension software (Biolin Scientific, Stockholm, Stockholm, Sweden).

\subsection{Activity against Streptococcus Mutans}

The antibacterial activity was evaluated for biofilm and planktonic bacteria against Streptococcus mutans (NCTC 10449). Three specimens per group were prepared for the biofilm test and three samples for the planktonic bacteria evaluation. Firstly, bacteria were prepared for the tests: $300 \mu \mathrm{L}$ of frozen S. mutans in skim milk was placed on a Petri dish containing brain heart infusion (BHI) broth with agar at $15 \mathrm{~g} / \mathrm{L}$ and kept in an oven, in a microaerophilic environment with $5 \%$ of $\mathrm{CO}_{2}$, at $37^{\circ} \mathrm{C}$ for $48 \mathrm{~h}$. The colonies were collected, placed in BHI broth containing $1 \mathrm{wt} . \%$ of sucrose and kept at $37^{\circ} \mathrm{C}$ for $24 \mathrm{~h}$ in the microaerophilic environment. The initial inoculum used for the tests was assessed by taking $100 \mu \mathrm{L}$ of the subcultured broth and mixing it with $900 \mu \mathrm{L}$ of a sterile saline solution $(0.9 \%)$ in an Eppendorf tube. A serial dilution was performed by vortexing the first to the sixth Eppendorf tube to dilute the solution until $10^{-6} \mathrm{~mL}$. The solutions were plated on BHI agar (two drops of $25 \mu \mathrm{L}$ ) and kept under the microaerophilic environment at $37^{\circ} \mathrm{C}$ for $48 \mathrm{~h}$. The colonies were visually counted and transformed in colony-forming units per milliliter $(\mathrm{CFU} / \mathrm{mL})$, indicating an inoculum used at $5 \times 10^{6} \mathrm{CFU} / \mathrm{mL}$. 
Subsequently, the antibacterial activity against biofilm formation on the polymerized specimens was evaluated. The specimens were fixed on the lid of a 48-well plate and sterilized using hydrogen peroxide plasma ( $58 \%$ ) for $48 \mathrm{~min}$ at $56^{\circ} \mathrm{C}$. In the sterile 48 -well plate, $100 \mu \mathrm{L}$ of the inoculum previously grown was inserted in each well with $900 \mu \mathrm{L}$ of BHI broth containing $1 \mathrm{wt} . \%$ of sucrose. The lid and the specimens were combined with the 48 -well plate base filled with the broth containing the bacteria and kept under $37^{\circ} \mathrm{C}$ for $24 \mathrm{~h}$ to form the biofilm on the top of the samples. Subsequently, the specimens were removed from the lid and placed in an Eppendorf with $1 \mathrm{~mL}$ of saline solution to be vortexed for $1 \mathrm{~min}$ and serially diluted, as previously stated. The diluted solutions were placed in Petri dishes with $\mathrm{BHI}$ agar to count the $\mathrm{CFU} / \mathrm{mL}$, as mentioned above and expressed in $\log \mathrm{CFU} / \mathrm{mL}$.

The broth with bacteria that was in contact with the samples for $24 \mathrm{~h}$ was used to evaluate the antibacterial activity against planktonic bacteria. From each well, $100 \mu \mathrm{L}$ were collected and inserted in Eppendorf tube with $900 \mu \mathrm{L}$ of saline solution to be vortexed, diluted until $10^{-6}$ and platted in BHI agar Petri dishes. Broth and S. mutans in three wells without samples' contact were used as a negative control. CFU/mL was counted and expressed in $\log \mathrm{CFU} / \mathrm{mL}$.

\subsection{Statistical Analysis}

The data were analyzed using the software SigmaPlot, version 12.0 (Systat Software, Inc., San Jose, CA, USA). Data distribution was evaluated by the Shapiro-Wilk test. Paired t-test was used to compare KHN1 and KHN2 in each group. Student t-test was used to compare groups in all tests at a level of 0.05 of significance.

\section{Results}

The values of degree of conversion (DC \%), initial and final Knoop hardness (KHN1, KHN2), softening in solvent $(\triangle \mathrm{KHN} \%)$ and ultimate tensile strength (UTS) of the experimental resin sealants are depicted in Table 1. It was possible to observe that the DC \% ranged from $49.67( \pm 4.47) \%$ to 51.08 $( \pm 3.17) \%$ without significant differences between the groups $(p>0.05)$. There was no significant difference for KHN1 $(p>0.05)$; all groups presented a decrease in the Knoop hardness after two hours of immersion in the ethanol solution $(p<0.05)$. The $\Delta$ KHN\% ranged from $62.64( \pm 4.98) \%$ to 65.02 $( \pm 4.83) \%$, but no significant difference was encountered between the groups $(p>0.05)$. When TAT and $\alpha$-TCP were incorporated into the experimental dental sealant, the mechanical property evaluated through UTS showed higher values in comparison to $\mathrm{G}_{\mathrm{CTRL}}(p<0.05)$.

Table 1. Mean and standard deviation values of degree of conversion (DC \%), microhardness before (KHN1) and after (KHN2) the immersion in the solvent, the variation of microhardness ( $\triangle \mathrm{KHN} \%)$ and ultimate tensile strength (UTS).

\begin{tabular}{cccccc}
\hline Group & DC $\%$ & KHN1 & KHN2 & $\Delta$ KHN\% & UTS (MPa) \\
\hline GCTRL $_{\text {C }}$ & $51.08( \pm 3.17)^{\mathrm{A}}$ & $16.41( \pm 0.97)^{\mathrm{Aa}}$ & $6.10( \pm 0.53)^{\mathrm{b}}$ & $62.64( \pm 4.98)^{\mathrm{A}}$ & $46.71( \pm 3.52)^{\mathrm{B}}$ \\
$\mathrm{G}_{\alpha \text {-TCPTAT }}$ & $49.67( \pm 4.47)^{\mathrm{A}}$ & $18.41( \pm 2.22)^{\mathrm{Aa}}$ & $6.40( \pm 0.83)^{\mathrm{b}}$ & $65.02( \pm 4.83)^{\mathrm{A}}$ & $55.61( \pm 3.33)^{\mathrm{A}}$ \\
\hline
\end{tabular}

Different capital letters indicate a statistical difference in the same column $(p<0.05)$. Different lowercase letters indicate a statistical difference in the same line for KHN1 and KHN2 of the same material $(p<0.05)$.

Figure 2 shows the polymerization behavior of the experimental dental sealants. The DC \% during time showed a slightly higher value of $D C \%$ for $G_{C T R L}$. The Rp versus time graph shows a delay in the polymerization reaction for $\mathrm{G}_{\alpha \text {-TCPTAT }}$ in comparison to $\mathrm{G}_{\mathrm{CTRL}}$. However, there was no significant difference for the conversion of carbon-carbon double bonds of the tested materials after 30 s of photoactivation, indicating that the addition of TAT and $\alpha$-TCP did not modify the DC $\%$ of the sealant. 
(A)

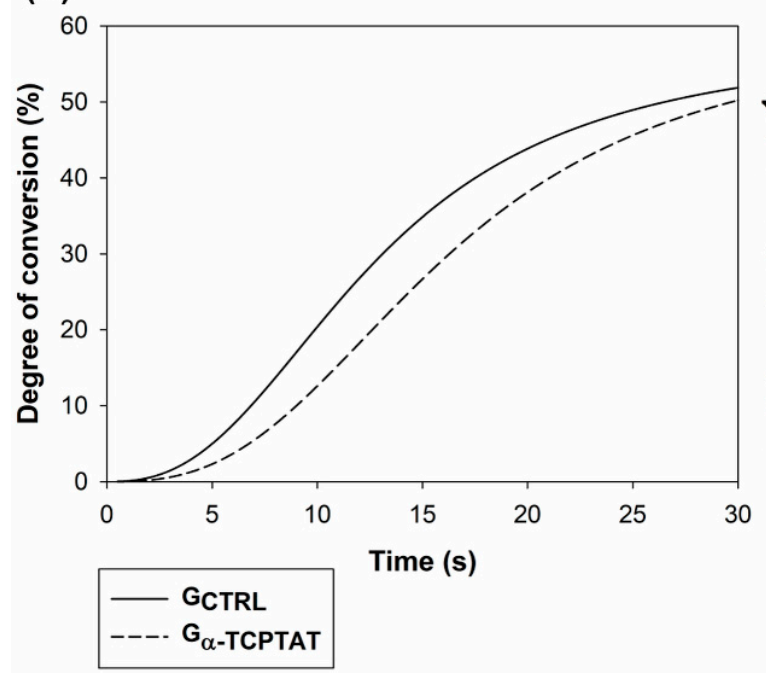

(B)

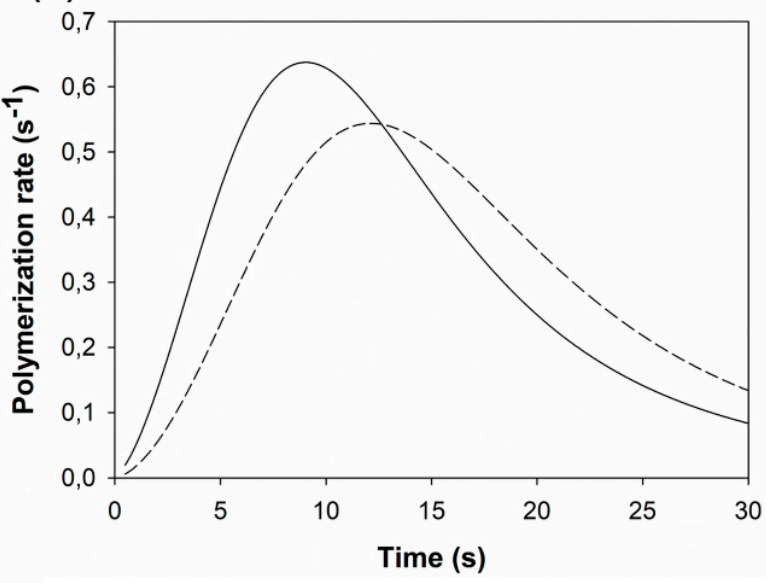

Figure 2. Polymerization behavior evaluation for $30 \mathrm{~s}$ of the experimental resin sealants. (A) DC \% versus photoactivation time. (B) Rp versus photoactivation time.

The values generated during the evaluation of the contact angle with water or $\alpha$-bromonaphthalene and SFE of the experimental dental sealants are presented in Table 2. The contact angle with water or $\alpha$-bromonaphthalene was not different between the tested groups $(p>0.05)$. The SFE ranged between $48.68( \pm 1.40) \mathrm{mN} / \mathrm{M}$ and $49.08( \pm 6.05) \mathrm{mN} / \mathrm{M}$, with no significant statistical difference between $\mathrm{G}_{\alpha \text {-TCPTAT }}$ and $\mathrm{G}_{\mathrm{CTRL}}(p>0.05)$.

Table 2. Mean and standard deviation values of contact angle with distilled water and $\alpha$-bromonaphthalene and surface free energy (SFE) of experimental sealant resins.

\begin{tabular}{cccc}
\hline Group & $\begin{array}{c}\text { Contact Angle } \\
(\text { Water })\end{array}$ & $\begin{array}{c}\text { Contact Angle } \\
(\alpha \text {-Bromonaphthalene) }\end{array}$ & SFE $(\mathbf{m N} / \mathbf{M})$ \\
\hline $\mathrm{G}_{\text {CTRL }}$ & $67.71( \pm 3.32)^{\mathrm{A}}$ & $24.69( \pm 3.09)^{\mathrm{A}}$ & $48.68( \pm 1.40)^{\mathrm{A}}$ \\
$\mathrm{G}_{\alpha \text {-TCPTAT }}$ & $66.49( \pm 10.9)^{\mathrm{A}}$ & $26.96( \pm 3.77)^{\mathrm{A}}$ & $49.08( \pm 6.05)^{\mathrm{A}}$ \\
\hline
\end{tabular}

Same capital letters indicate no statistical difference in the same column $(p>0.05)$.

Table 3 displays the antibacterial effect against Streptococcus mutans. GCTRL presented $6.38( \pm 0.57)$

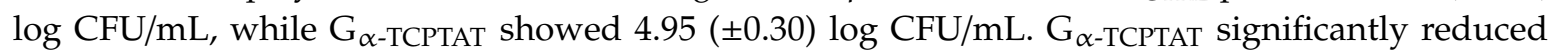
bacterial growth on the surface of the polymerized sealants in comparison to $\mathrm{G}_{\mathrm{CTRL}}(p<0.05)$. $\mathrm{G}_{\alpha \text {-TCPTAT }}$ also showed a significant reduction of planktonic bacteria viability when compared to $\mathrm{G}_{\mathrm{CTRL}}$ and negative control $(p<0.05)$.

Table 3. Mean and standard deviation values of log-transformed colony-forming units/ $\mathrm{mL}(\mathrm{CFU} / \mathrm{mL})$ for bacteria in biofilm or planktonic bacteria after the contact during $24 \mathrm{~h}$ with the experimental dental sealants.

\begin{tabular}{ccc}
\hline \multirow{2}{*}{ Group } & \multicolumn{2}{c}{ Effect against S. Mutans } \\
\cline { 2 - 3 } & Biofilm & Planktonic Bacteria \\
\hline G $_{\text {CTRL }}$ & $06.38( \pm 0.57)^{\mathrm{A}}$ & $09.21( \pm 0.14)^{\mathrm{A}}$ \\
G $_{\alpha \text {-TCPTAT }}$ & $04.95( \pm 0.30)^{\mathrm{B}}$ & $07.73( \pm 0.56)^{\mathrm{B}}$ \\
Negative control & - & $09.14( \pm 0.10)^{\mathrm{A}}$ \\
\hline
\end{tabular}

Different capital letters indicate a statistical difference between groups in the same column $(p<0.05)$. 


\section{Discussion}

Resin-based sealants are effective in preventing and reducing caries because they work as a physical barrier that prevents tooth demineralization [3]. The antibacterial monomer TAT and $\alpha$-TCP, a remineralizing agent (Figure 3), were incorporated at $2 \mathrm{wt} \%$ each in an experimental resin sealant.

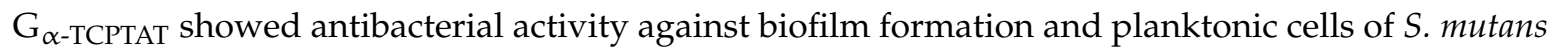
and increased the UTS values without compromising the physicochemical properties of the sealant.

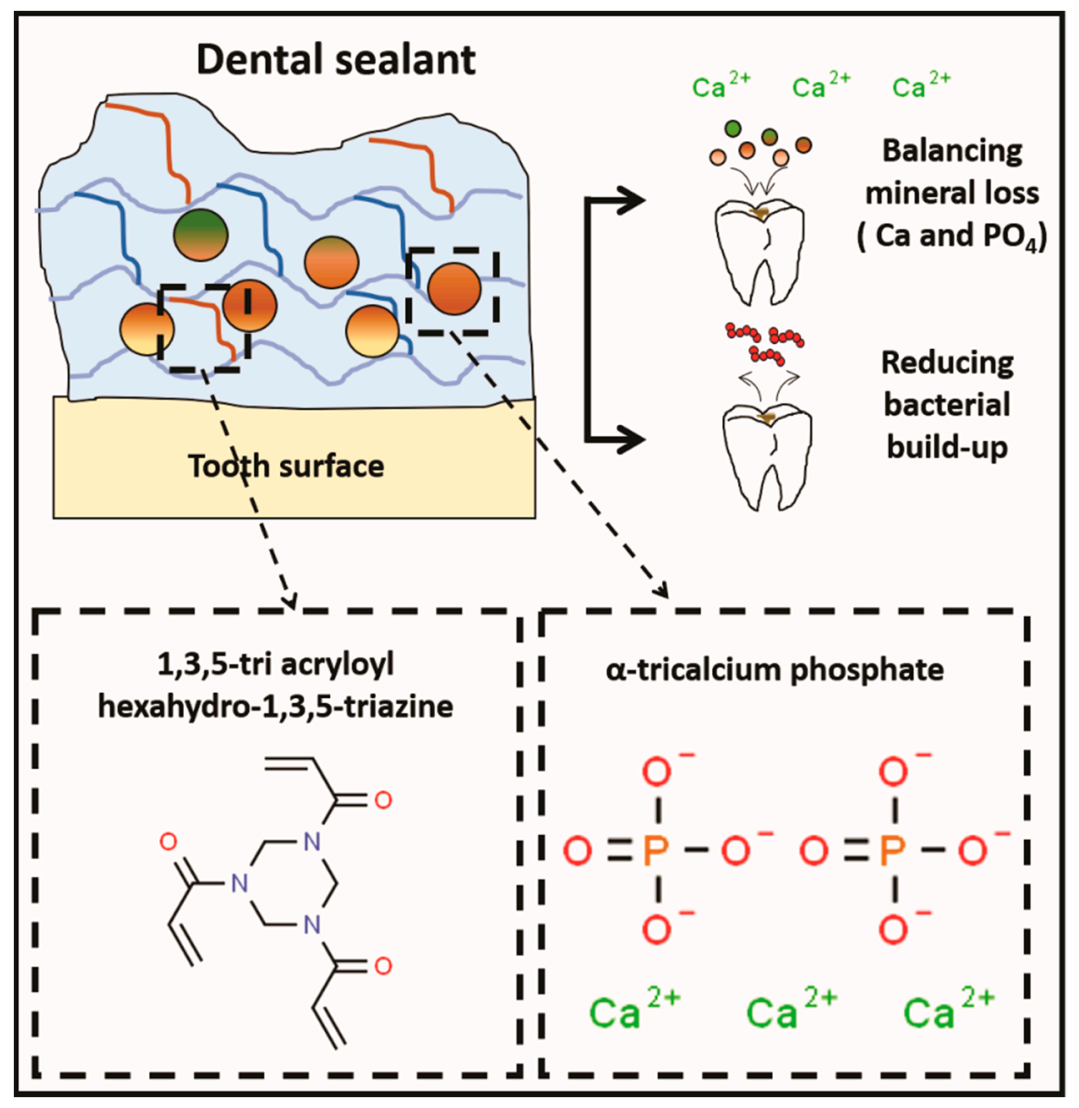

Figure 3. Schematic draw of the dental sealant formulated and analyzed in the present research, containing an antibacterial and a bioactive agent.

All the experimental resin sealants were formulated and evaluated regarding the polymerization kinetics and DC \% by FTIR-ATR. DC \% represents the percentage of carbon double bond conversion and high values are associated with better mechanical properties and reduced matrix degradation [16]. TAT is a tri-functional monomer, presenting three aliphatic double bonds $(\mathrm{C}=\mathrm{C})$ that are able to copolymerize, which may also increase double bond conversion [9]. In the polymerization kinetics regarding DC \% per time, no significant statistical difference was observed between the tested groups. On the other hand, at the polymerization rate per time analysis, the difference can be observed in

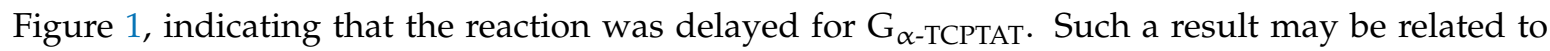
an increase of resin sealant viscosity, as well as to the decrease of monomers mobility for $G_{\alpha \text {-TCPTAT, }}$ leading to a non-difference of DC \% between groups even with the addition of this trifunctional

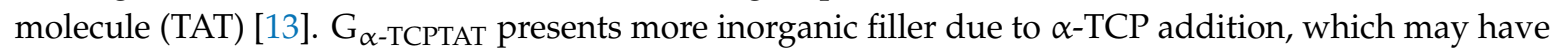
caused a reduction of the transmission of the light during the light-curing procedures, so reducing the DC \% compared to GCTRL [17]. The presence of TAT may have made it possible to incorporate a filler $(\alpha$-TCP) with a very different refractive index than the resin matrix without changing the polymerization degree. Nevertheless, both groups achieved reliable DC \%, with values comparable to those of resin sealants currently available in the dental market [18]. 
TAT has been used to synthesize materials with better chemical and physical properties $[7,8]$. In the current study, the Knoop hardness and the softening in solvent, which can be related to polymers' crosslinking density, showed no differences between groups. A lower concentration of TAT was used than the previous studies [9], which could lead to no detectable differences in Knoop hardness. This test evaluates a superficial characteristic of the material and it can change polymers' values due to the load pressure on inorganic fillers (such as calcium tungstate and calcium phosphate) in the softer organic matrix. Thus, it may not measure the intrinsic value of the crosslinked resin [19] due to the presence of more amount of fillers.

Conversely, the mechanical properties (ultimate tensile strength) of $G_{\alpha \text {-TCPTAT were greater than }}$ those observed in the $\mathrm{G}_{\mathrm{CTRL}}$. This mechanical improvement may be related to higher crosslinking density with TAT, although no significant difference was found for DC \% or Knoop hardness. The presence of higher filler content $(\alpha-\mathrm{TCP})$ can increase the mechanical properties of composite materials [20], such as the experimental dental sealant tested in this study. However, agglomerated inorganic fillers within the polymer could also increase internal defects in the materials, leading to reduced mechanical properties [21]. The results of UTS may indicate the homogeneous dispersion of filler particles in the groups containing $\alpha-\mathrm{TCP}$ and TAT. These were promising results since it is desired that resin sealants present reliable mechanical properties to offer suitable resistance when receiving loads in occlusal dental surfaces during masticatory forces. It is well known that mechanical tests under static or dynamic loading can induce different outcomes for materials' behavior [22]. With the promising results observed for the composite with TAT here formulated, further studies may be performed to analyze its mechanical properties considering different designs.

The incorporation of fillers in polymers may also change the contact angle and surface free energy (SFE) [23]. Besides, a previous study showed that the penetration coefficient (PC) of commercial sealants is correlated to their ability to penetrate fissures. The PC equation was composed of the liquid's surface tension to air, the cosine of the liquid's contact angle to enamel and the dynamic viscosity of the fluid. Therefore, at low contact angle values, a high sealant PC can be achieved [24]. $G_{\alpha T C P T A T}$ had no significant influence on SFE and contact angle, which probably lead to an increased PC.

QACs have been studied due to their high and broad antibacterial spectra, even at small concentrations [25-27]. In the case of TAT, it was suggested that the mechanism of antibacterial action is due to "contact killing" effect [6]. QACs are positively charged due to a lack of electrons in the nitrogen atom, which provides an electrostatic interaction with the negatively charged bacteria's membrane/wall. This event possibly leads to a disruption of bacteria membrane and loss of intracellular components, as previously shown for other QACs [28]. In this study, $\mathrm{G}_{\alpha \text {-TCPTAT }}$ reduced bacterial growth on the surface of the polymerized samples compared to $\mathrm{G}_{\mathrm{CTRL}}$, corroborating to previous analyses of TAT in resins [7-9]. $G_{\alpha \text {-TСРТАT }}$ also reduced the number of planktonic bacteria, similar to other studies with copolymerized QAC [29]. It is a limitation of this study that the sealant was not tested against a complex multi-species biofilm, which would better mimic a clinical situation [30]. However, here we tested the effect of a novel sealant against a bacterium positively correlated with dental caries (S. mutans) [31] and the results encourage further evaluation in situ and in vivo.

\section{Conclusions}

Dental sealants empowered by 1,3,5-tri acryloyl hexahydro-1,3,5-triazine and $\alpha$-tricalcium phosphate for anti-caries application presented lower bacterial growth and tensile strength. Moreover, such an experimental material formulated with antibacterial and bioactive agents showed higher resistance against the ethanol softening ageing. The combinatorial effect of bioactive and antibacterial agents might impair the developed material with dual effect-prevention and treatment of non-cavitated caries lesions on occlusal and proximal surfaces. Therefore, the innovative bioactive dental material here proposed may represent an exciting approach to contribute to the development of new anti-caries dental materials. 
Author Contributions: Conceptualization, F.M.C. and V.C.B.L.; Formal analysis, F.M.C., J.C.M., M.S. and I.M.G.; Investigation, F.M.C., V.C.B.L., J.C.M., M.S. and I.M.G.; Supervision, F.M.C., V.C.B.L.; Writing-Original Draft Preparation, J.C.M., M.S. and I.M.G.; Validation, S.S., F.M.C. and V.C.B.L. Writing-Review \& Editing, F.M.C.; V.C.B.L.; S.S.; M.A.M. All authors have read and agreed to the published version of the manuscript.

Funding: This research received no external funding.

Acknowledgments: This study was financed in part by the Coordenação de Aperfeiçoamento de Pessoal de Nível Superior-Brasil (CAPES) - Finance Code 001. We also would like to acknowledge lab technician Luisa Mercado for assistance and availability in the Biochemistry and Microbiology Laboratory (LABIM).

Conflicts of Interest: The authors declare no conflict of interest.

\section{References}

1. Petersen, P.E.; Bourgeois, D.; Ogawa, H.; Estupinan-Day, S.; Ndiaye, C. The global burden of oral diseases and risks to oral health. Bull. World Health Organ. 2005, 83, 661-669. [PubMed]

2. Hicks, J.; Garcia-Godoy, F.; Flaitz, C. Biological factors in dental caries: Role of saliva and dental plaque in the dynamic process of demineralization and remineralization (part 1). J. Clin. Pediatric Dent. 2003, 28, 47-52. [CrossRef] [PubMed]

3. Ahovuo-Saloranta, A.; Forss, H.; Walsh, T.; Nordblad, A.; Makela, M.; Worthington, H.V. Pit and fissure sealants for preventing dental decay in permanent teeth. Cochrane Database Syst. Rev. 2017, 7, Cd001830. [CrossRef] [PubMed]

4. Kuhnisch, J.; Mansmann, U.; Heinrich-Weltzien, R.; Hickel, R. Longevity of materials for pit and fissure sealing-results from a meta-analysis. Dent. Mater. 2012, 28, 298-303. [CrossRef] [PubMed]

5. Ibrahim, M.S.; AlQarni, F.D.; Al-Dulaijan, Y.A.; Weir, M.D.; Oates, T.W.; Xu, H.H.K.; Melo, M.A.S. Tuning Nano-Amorphous Calcium Phosphate Content in Novel Rechargeable Antibacterial Dental Sealant. Materials 2018, 11, 1544. [CrossRef]

6. Zhou, C.; Min, J.; Liu, Z.; Young, A.; Deshazer, H.; Gao, T.; Chang, Y.T.; Kallenbach, N.R. Synthesis and biological evaluation of novel 1,3,5-triazine derivatives as antimicrobial agents. Bioorg. Med. Chem. Lett. 2008, 18, 1308-1311. [CrossRef]

7. Schiroky, P.R.; Leitune, V.C.B.; Garcia, I.M.; Ogliari, F.A.; Samuel, S.M.W.; Collares, F.M. Triazine Compound as Copolymerized Antibacterial Agent in Adhesive Resins. Braz. Dent. J. 2017, 28, 196-200. [CrossRef]

8. Altmann, A.S.; Collares, F.M.; Leitune, V.C.; Arthur, R.A.; Takimi, A.S.; Samuel, S.M. In vitro antibacterial and remineralizing effect of adhesive containing triazine and niobium pentoxide phosphate inverted glass. Clin. Oral Investig. 2017, 21, 93-103. [CrossRef]

9. Altmann, A.S.; Collares, F.M.; Ogliari, F.A.; Samuel, S.M. Effect of methacrylated-based antibacterial monomer on orthodontic adhesive system properties. Am. J. Orthod. Dentofac. Orthop. 2015, 147, S82-S87. [CrossRef]

10. Cocco, A.R.; Rosa, W.L.; Silva, A.F.; Lund, R.G.; Piva, E. A systematic review about antibacterial monomers used in dental adhesive systems: Current status and further prospects. Dent. Mater. 2015, 31, 1345-1362. [CrossRef]

11. Khan, A.S.; Syed, M.R. A review of bioceramics-based dental restorative materials. Dent. Mater. J. 2019, 38, 163-176. [CrossRef]

12. Garcia, I.M.; Leitune, V.C.B.; Samuel, S.M.W.; Collares, F.M. Influence of Different Calcium Phosphates on an Experimental Adhesive Resin. J. Adhes. Dent. 2017, 19, 379-384.

13. Tezvergil-Mutluay, A.; Seseogullari-Dirihan, R.; Feitosa, V.P.; Cama, G.; Brauer, D.S.; Sauro, S. Effects of composites containing bioactive glassess on demineralized dentin. J. Dent. Res. 2017,96,999-1005. [CrossRef] [PubMed]

14. Collares, F.M.; Portella, F.F.; Leitune, V.C.; Samuel, S.M. Discrepancies in degree of conversion measurements by FTIR. Braz. Oral Res. 2013, 27, 453-454. [PubMed]

15. Owens, D.K.; Wends, R.C. Estimation of the surface free energy of polymers. J. Appl. Polym. Sci. 1969, 13, 1741-1747. [CrossRef]

16. Collares, F.M.; Ogliari, F.A.; Zanchi, C.H.; Petzhold, C.L.; Piva, E.; Samuel, S.M. Influence of 2-hydroxyethyl methacrylate concentration on polymer network of adhesive resin. J. Adhes. Dent. 2011, 13, 125-129.

17. Taira, M.; Suzuki, H.; Toyooka, H.; Yamaki, M. Refractive index of inorganic fillers in seven visible-light-cured dental composite resins. J. Mater. Sci. 1994, 13, 68-70. [CrossRef] 
18. Utneja, S.; Talwar, S.; Nawal, R.R.; Sapra, S.; Mittal, M.; Rajain, A.; Verma, M. Evaluation of remineralization potential and mechanical properties of pit and fissure sealants fortified with nano-hydroxyapatite and nano-amorphous calcium phosphate fillers: An in vitro study. J. Conserv. Dent. 2018, 21, 681-690. [CrossRef]

19. Krumova, M.; Klingshirn, C.; Friedrich, K. Microhardness studies on functionally graded polymer composites. Compos. Sci. Technol. 2001, 61, 557-563. [CrossRef]

20. Yadav, R.; Kumar, M. Dental restorative composite materials: A review. J. Oral Biosci. 2019, 61, 78-83. [CrossRef]

21. Lohbauer, U.; Wagner, A.; Belli, R.; Stoetzel, C.; Hilpert, A.; Kurland, H.D.; Grabow, J.; Müller, F.A. Zirconia nanoparticles prepared by laser vaporization as fillers for dental adhesives. Acta Biomater. 2010, 6, 4539-4546. [CrossRef] [PubMed]

22. Khosravani, M.R. Mechanical behavior of restorative dental composites under various loading conditions. J. Mech. Behav. Biomed. Mater. 2019, 93, 151-157. [CrossRef] [PubMed]

23. Degrazia, F.W.; Leitune, V.C.B.; Samuel, S.M.W.; Collares, F.M. Boron nitride nanotubes as novel fillers for improving the properties of dental adhesives. J. Dent. 2017, 62, 85-90. [CrossRef] [PubMed]

24. Paris, S.; Meyer-Lueckel, H.; Colfen, H.; Kielbassa, A.M. Penetration coefficients of commercially available and experimental composites intended to infiltrate enamel carious lesions. Dent. Mater. 2007, 23, 742-748. [CrossRef]

25. Mena Silva, P.A.; Garcia, I.M.; Nunes, J.; Visioli, F. Myristyltrimethylammonium Bromide (MYTAB) as a Cationic Surface Agent to Inhibit Streptococcus mutans Grown over Dental Resins: An In Vitro Study. J. Funct. Biomater. 2020, 11, 9. [CrossRef]

26. Ibrahim, M.S.; Ibrahim, A.S.; Balhaddad, A.A.; Weir, M.D.; Lin, N.J.; Tay, F.R.; Oates, T.W.; Xu, H.H.K.; Melo, M.A.S. A Novel Dental Sealant Containing Dimethylaminohexadecyl Methacrylate Suppresses the Cariogenic Pathogenicity of Streptococcus mutans Biofilms. Int. J. Mol. Sci. 2019, 20, 3491. [CrossRef]

27. Imazato, S.; Kinomoto, Y.; Tarumi, H.; Ebisu, S.; Tay, F.R. Antibacterial activity and bonding characteristics of an adhesive resin containing antibacterial monomer MDPB. Dent. Mater. 2003, 19, 313-319. [CrossRef]

28. Makvandi, P.; Jamaledin, R.; Jabbari, M.; Nikfarjam, N.; Borzacchiello, A. Antibacterial quaternary ammonium compounds in dental materials: A systematic review. Dent. Mater. 2018, 34, 851-867. [CrossRef]

29. Wang, S.; Zhang, K.; Zhou, X.; Xu, N.; Xu, H.H.; Weir, M.D.; Ge, Y.; Wang, S.; Li, M.; Li, Y.; et al. Antibacterial effect of dental adhesive containing dimethylaminododecyl methacrylate on the development of Streptococcus mutans biofilm. Int. J. Mol. Sci. 2014, 15, 12791-12806. [CrossRef]

30. Kreth, J.; Ferracane, J.L.; Pfeifer, C.S.; Khajotia, S.; Merritt, J. At the Interface of Materials and Microbiology: A Call for the Development of Standardized Approaches to Assay Biomaterial-Biofilm Interactions. J. Dent. Res. 2019, 98, 850-852. [CrossRef]

31. Kirstila, V.; Hakkinen, P.; Jentsch, H.; Vilja, P.; Tenovuo, J. Longitudinal analysis of the association of human salivary antimicrobial agents with caries increment and cariogenic micro-organisms: A two-year cohort study. J. Dent. Res. 1998, 77, 73-80. [CrossRef] [PubMed]

(C) 2020 by the authors. Licensee MDPI, Basel, Switzerland. This article is an open access article distributed under the terms and conditions of the Creative Commons Attribution (CC BY) license (http://creativecommons.org/licenses/by/4.0/). 